\title{
Optimum Structure Adjustment for Flexible Fluorescent and Phosphorescent Organic Light Emitting Diodes
}

\author{
Fuh-Shyang Juang, Yu-Sheng Tsai, Shun-Hsi Wang, \\ Shin-Yuan Su, Shin-Liang Chen and Shen-Yaur Chen \\ National Formosa University \\ Taiwan
}

\section{Introduction}

The organic light emitting diodes (OLEDs) [1] is a new-generation flat panel display with the advantages of self-luminescence, wide viewing angle $\left(>160^{\circ}\right)$, prompt response time $(\sim 1$ $\mu \mathrm{s})$, low operating voltage (3 10 V), high luminance efficiency, high color purity, and easy to be made on various substrates. Therefore, it's an important topic that how to improve the luminance efficiency, lifetime and the adhesion characters of ITO/organic interface of flexible OLEDs. Zugang Liu et al. reported that the NPB (HTL) is suitable in contact with the emission layer and when they form an energy ladder structure, the driving voltage decreased and the electroluminescent output increased [2]. Thus it can be seen, the hole transport layer [3-6] is very important to balance the injection of hole and electron, to increase the luminance efficiency and lifetime. In recent years, the hole buffer layer of device typically employs LiF [7], CuPc [8], Pani:PSS [9-10] or PEDOT:PSS [9-11] to improve the hole injection efficiency. In addition, a flexible substrate (PET, metal foil, etc.) surface is not completely smooth and will usually have spikes. After the organic thin film evaporates onto the ITO substrate surface the spikes will still exist. When the device is operated under high voltage or high current density, a heavy amount of electric current will concentrate at the spikes and damage the device by causing the device to short circuit, creating Joule heat. The luminance efficiency of the device will therefore be reduced producing shorter device lifetime. Thus, the PEDOT:PSS fabrication process uses spin-coating to obtain a thin film with a smoother surface than that produced by thermal deposition. Spin-coating enhances the organic material adhesion in subsequent processes, thereby directly affecting the performance of flexible OLED. For the above reason, this research dissolved hole transport material $\mathrm{N}, \mathrm{N}^{\prime}$-diphenyl-N,N'-bis(1-naphthyl)- 1,1'biphenyl-4,4"'diamine (a-NPD), N,N'Bis(naphthalene- l-yl) -N,N'-bis(phenyl)-benzidine (NPB) or a-NPD:NPB in tetrahydrfuran (THF) solvent and spin-coated the buffer layer onto ITO surface of flexible OLEDs. Phosphorescent dye gains energy from the radiative recombination of both singlet and triplet excitons [12], improving the internal quantum efficiency of fluorescent OLEDs (FOLEDs) typically $25 \%$ at maximum to nearly 100\% [13]. Enhancing the luminance 
efficiency of phosphorescent OLED has attracted the interest of many researchers. Improving device efficiency, the triplet state excitons must be confined in the emitting layer to increase the chance for energy transfer from host to guest. The material that achieves this effect is called the hole blocking layer (HBL), CF-X [14], CF-Y [14], BCP [12], TPBi [15], and BAlq [16]. These materials have higher ionization energy and band gap that can block the diffusion of excitons. When the host-guest orbit overlap is weak, the blocking layer action is particularly important.

\section{Experiment}

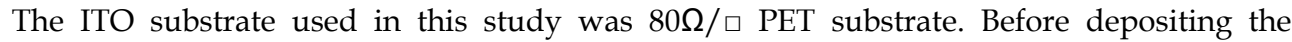
patterned ITO substrate was placed in $\mathrm{O}_{2}$ plasma for surface cleaning. The spin-coating solvents were then prepared by dissolving hole transport materials $\mathrm{N}, \mathrm{N}^{\prime}$-diphenyl- $\mathrm{N}, \mathrm{N}^{\prime}$ bis(1-naphthyl)- 1,1'biphenyl-4,4'diamine (a-NPD) and N, $\mathrm{N}^{\prime}$-Bis(naphthalene-l-yl) - $\mathrm{N}^{\prime} \mathrm{N}^{\prime}$ bis(phenyl)-benzidine (NPB) (a-NPD mixed NPB with 1:1 wt\%) in tetrahydrfuran (THF) solvent. The chemicals are vibrated ultrasonically in solution for 60 minutes to facilitate the dissolving process. The coating process is then carried out for 35 seconds at 4500 r.p.m. to deposit the buffer layer onto the ITO surface. After that the substrate was placed in an organic evaporation chamber to deposit the organic layers under $2 \times 10^{-6}$ torr, a-NPD or NPB was deposited as hole transport layer (HTL), 4,4'-Bis(carbazol-9-yl) biphenyl (CBP) was deposited as the phosphorescent device host, Tris(2-pheny-lpyridine) iridium(III) (Ir(ppy)3) was deposited as the phosphorescent device guest material, 2,9-Dime-thyl-4,7-diphenyl1,10-phenanhroline (BCP) or 2,2',2"-(1,3,5-Benzinetriyl) -tris(1-phenyl-1-H-benzimidazole) (TPBi) was deposited as the hole blocking layer (HBL), Tris(8-hydroxyquinolinato)aluminum (Alq3) was deposited as emitting layer (EML) of fluorescent and electron transport layer (ETL), and 1,3-Bis[2-(2,2'-bipyridine-6-yl)-1,3,4-oxadiazo-5yl]benzene (Bpy-OXD) was deposited as electron transport layer/ hole blocking layer. The chemical structures of all used organic materials are shown in Fig. 1. SpectraScan PR650 and Keithley 2400 equipment were employed to measure the luminance and current-voltage characteristics.

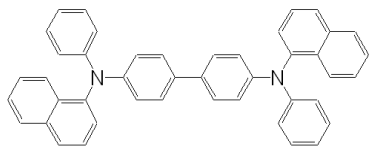

(a)

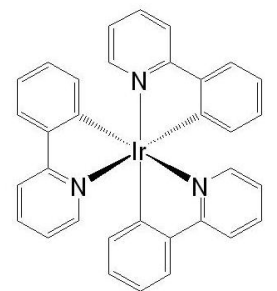

(d)

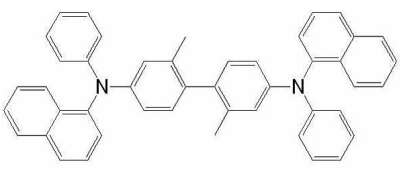

(b)

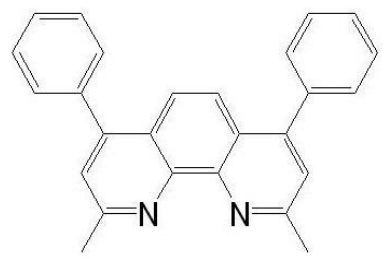

(e)

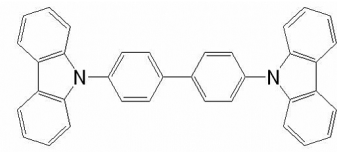

(c)

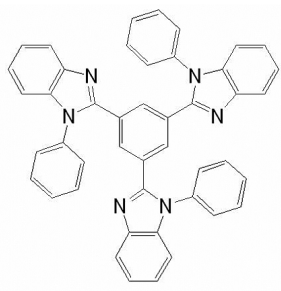

(f) 


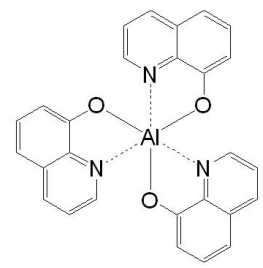

(g)

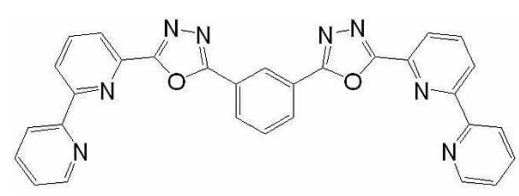

(h)

Fig. 1. The chemical structures of all used organic materials (a) NPB, (b) a-NPD, (c) CBP, (d) $\operatorname{Ir}($ ppy) 3 , (e) BCP, (f) TPBi, (g) Alq3 and (h) Bpy-OXD

\section{Results and discussion}

\subsection{Optimum Structure Adjustment for Flexible Phosphorescent Organic Light} Emitting Diodes

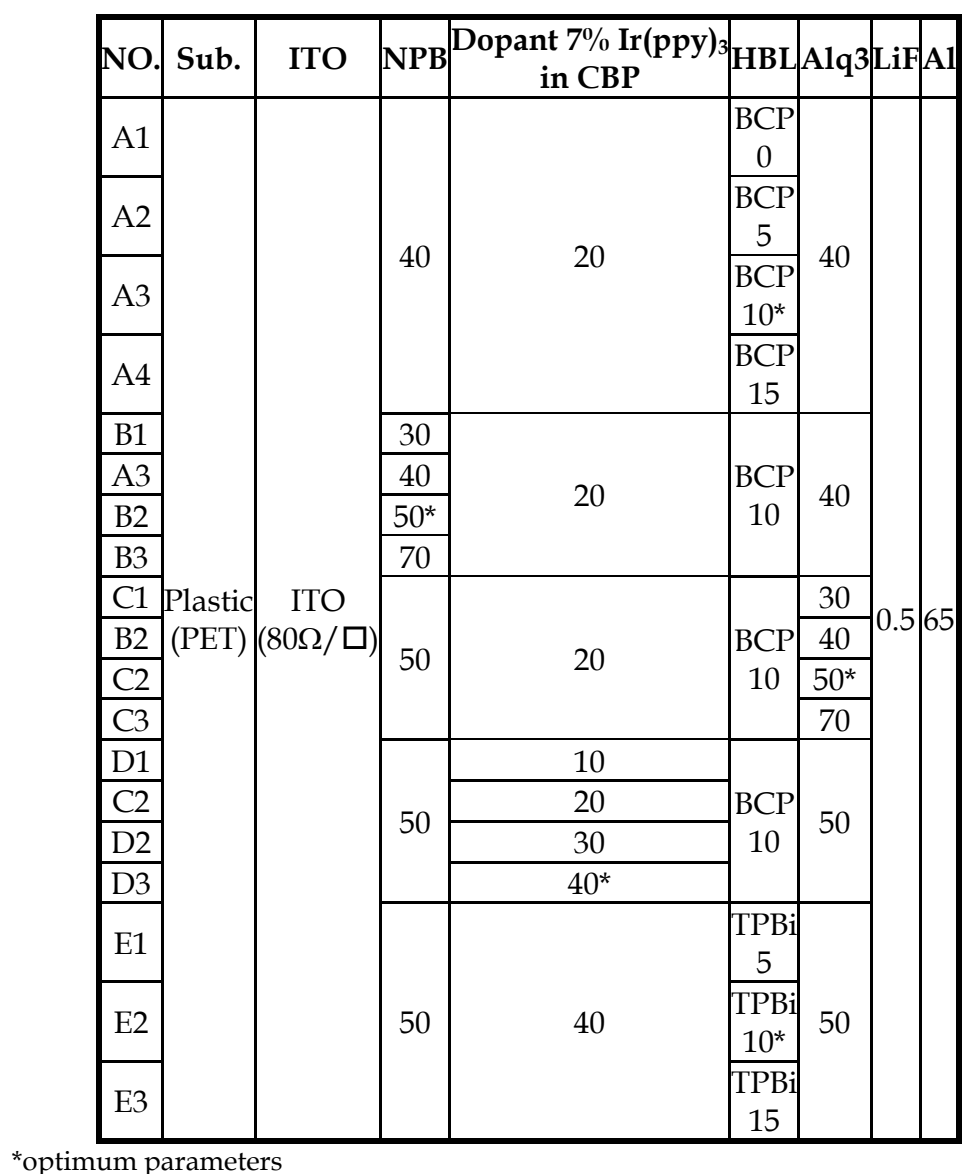

Table 1. Adjustment parameters of Phosphorescent organic light emitting diodes (unit: nm) 
In this study the device structures are shown in Table 1. First, we inserted a hole blocking layer (HBL) to effectively confine the holes in the emitting layer (EML) for improving the luminance efficiency of the devices. Moreover, varied the thickness of $\mathrm{BCP}$ from 0 to $15 \mathrm{~nm}$; it was found that the best hole-blocking result was present at $10 \mathrm{~nm}$ of the thickness of $\mathrm{BCP}$ (as shown in Fig.1). However, if the thickness of BCP was increased to $15 \mathrm{~nm}$, the hole blocking result was better, but the distance of injecting electrons to EML was increased and caused the brightness decreased. Then, we tried to vary the thickness of NPB to make the amount of the hole injected into EML match with the amount of the electron for increasing the luminance efficiency of the device. From Fig. 2, it was found that the maximum luminance efficiency of the device can be obtained at $50 \mathrm{~nm}$ of the thickness of NPB. Furthermore, we varied the thickness of Alq3 to make the amount of the electron injected into EML match with the amount of the hole. From Fig. 3, it was found that the maximum luminance efficiency of the device can be obtained at $50 \mathrm{~nm}$ of the thickness of Alq3. However, if the thickness of Alq3 was increased to $70 \mathrm{~nm}$, the distance of the electron injecting to EML was enhanced to decrease the amount of the electron injected into the EML to cause the brightness greatly decreased. At last, we varied the thickness of the EML of CBP:Ir(ppy) 3 from $10 \mathrm{~nm}$ to $40 \mathrm{~nm}$ and hoped that the chance of recombining electron-hole will be increased via varying the thickness of the EML to increase the brightness and luminance efficiency. From the experiment result, it was found that the best luminance efficiency would be obtained at the layer thickness of $40 \mathrm{~nm}$ (as shown in Fig. 4); at the moment, the device efficiency was greatly increased to $30.4 \mathrm{~cd} / \mathrm{A}$.

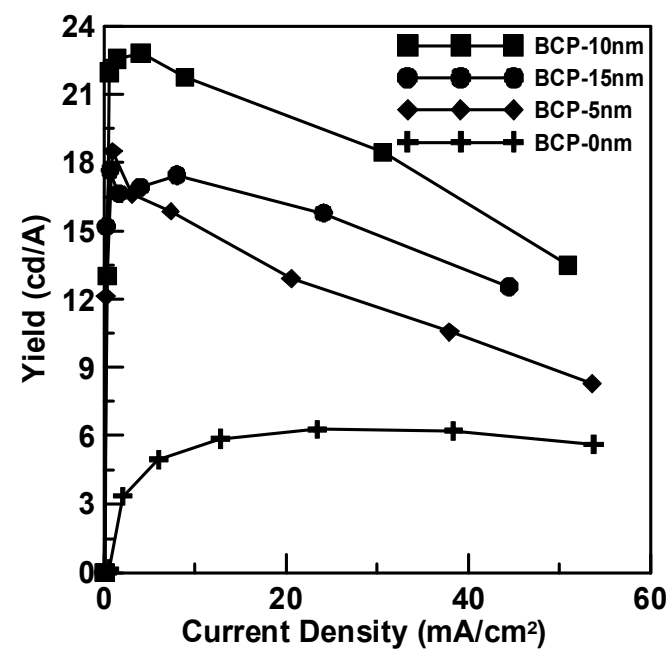

Fig. 1. Luminance efficiency-current density curves for different thicknesses of HBL 


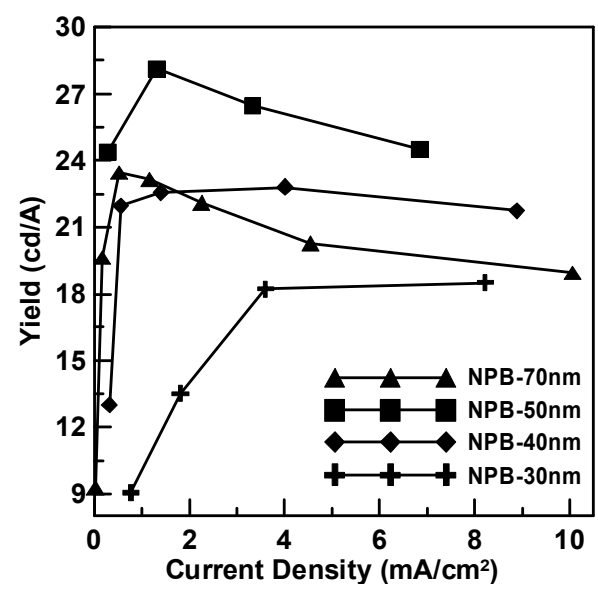

Fig. 2. Luminance efficiency-current density curves for different thicknesses of HTL

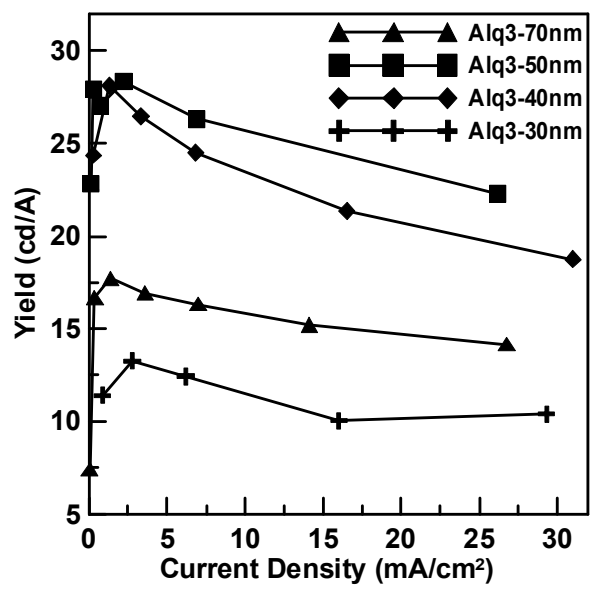

Fig. 3. Luminance efficiency-current density curves for different thicknesses of ETL 


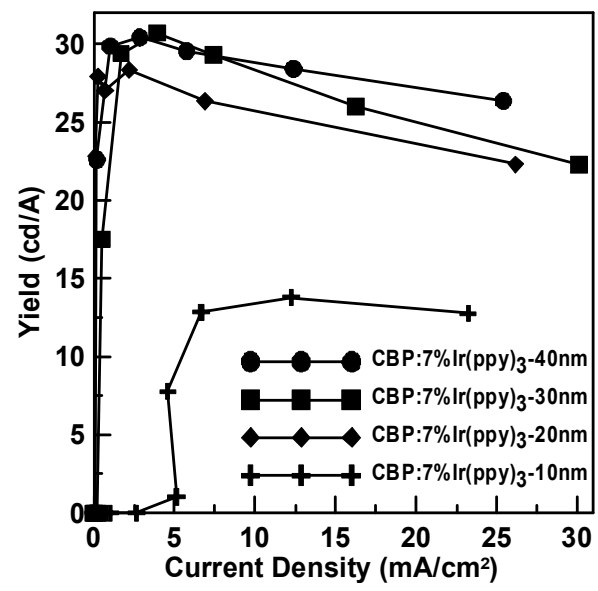

Fig. 4. Luminance efficiency-current density curves for different thicknesses of EML

Finally the doping concentration of $\left(\operatorname{Ir}(\mathrm{ppy})_{3}\right)$ was adjusted as shown in Table 2. We found in Fig. 5 that when the doping concentration was $7 \mathrm{wt} \%$ the device has optimum luminance efficiency. In this study we also changed different hole blocking layers (HBL) BCP and TPBi, whose structures are shown in Table 1, respectively. It is found from luminance efficiency current density in Fig. 5 that using TPBi as hole blocking layer could enhance the luminance efficiency further to $34.2 \mathrm{~cd} / \mathrm{A}$. This is because the HOMO of TPBi $(6.7 \mathrm{eV})$ is higher than the HOMO of BCP $(6.3 \mathrm{eV})$, which confines holes and excitons in the emitting layer more effectively and prevents direct diffusion of holes or excitons to Alq3 layer. After comparing the effects of different HBLs on luminance efficiency as shown in Fig. 5, it is found a suitable material of HBL can improve the luminance efficiency of device effectively.

From the results of these serial experiments, it is found that whenever the thickness of an organic layer has been adjusted, the luminance efficiency of the device has increased (as shown in Fig. 6). It is because the amount of electron-hole of the device becomes more balanced via the optimization of the hole transport layer and the electron transport layer. In addition, extending the charge carrier recombining area and using more suitable HBL material and suitable thickness of its thin film will gradually increase and improve the luminance efficiency of the device.

\begin{tabular}{|c|c|c|c|c|c|c|c|c|c|}
\hline \multirow[b]{2}{*}{ NO. } & \multirow[b]{2}{*}{ Sub. } & \multirow[b]{2}{*}{ ITO } & \multirow[b]{2}{*}{ NPB } & \multicolumn{2}{|c|}{$\operatorname{Ir}(\text { ppy) })_{3}:$ CBP } & \multirow[b]{2}{*}{ HBL } & \multirow[b]{2}{*}{ Alq3 } & \multirow[b]{2}{*}{$\mathrm{LiF}$} & \multirow[b]{2}{*}{ Al } \\
\hline & & & & $\begin{array}{c}\text { concen } \\
.\end{array}$ & thickness & & & & \\
\hline F1 & \multirow{4}{*}{$\begin{array}{c}\text { Plastic } \\
(\text { PET })\end{array}$} & \multirow{4}{*}{$\begin{array}{c}\mathrm{ITO} \\
(80 \Omega / \square)\end{array}$} & \multirow{4}{*}{50} & $4 \%$ & \multirow{4}{*}{40} & \multirow{4}{*}{$\begin{array}{c}\text { BCP } \\
10\end{array}$} & \multirow{4}{*}{50} & \multirow{4}{*}{0.5} & \multirow{4}{*}{65} \\
\hline D3 & & & & $7 \% *$ & & & & & \\
\hline F2 & & & & $8 \%$ & & & & & \\
\hline F3 & & & & $10 \%$ & & & & & \\
\hline
\end{tabular}

*optimum parameters

Table 2. Adjustment parameters of PHOLEDs with different $\operatorname{Ir}(\mathrm{ppy})_{3}$ doping concentrations (unit: $\mathrm{nm}$ ) 


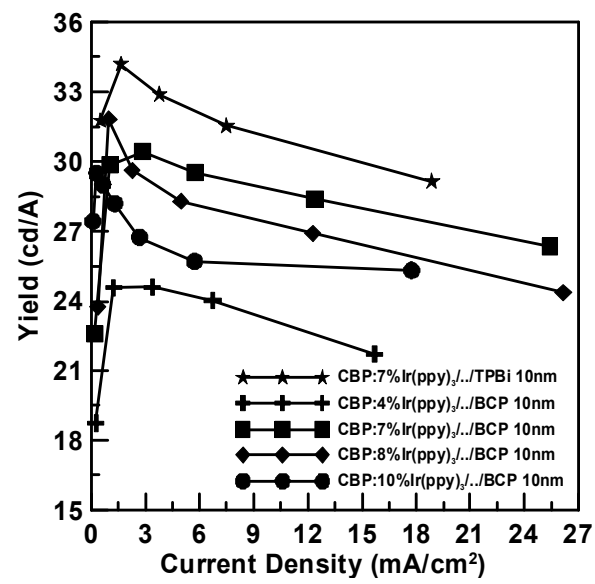

Fig. 5. Luminance efficiency-current density curves of PHOLEDs with different $\operatorname{Ir}(\mathrm{ppy})_{3}$ doping concentrations and HBL materials

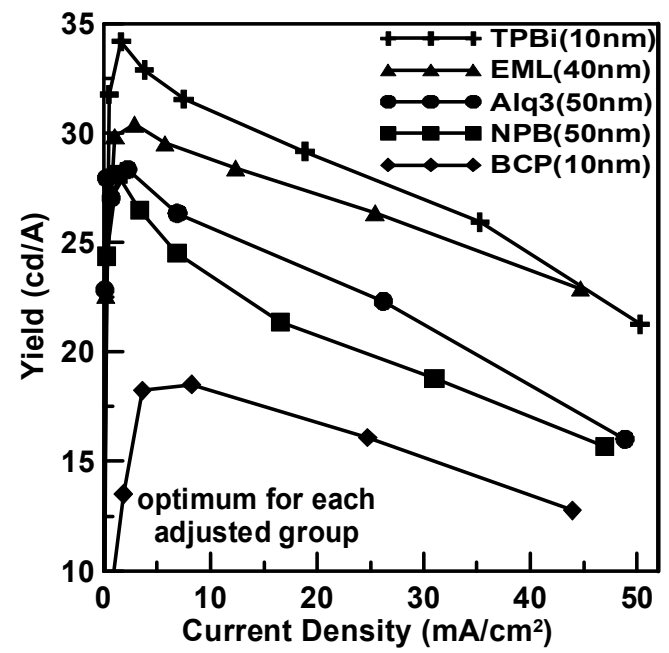

Fig. 6. Luminance efficiency-current density of optimum thickness for each adjusted layer

\subsection{Spin-coating ( $\alpha-N P D: N P B)+T H F$ as the buffer layer and evaporating NPB as the hole transport layer to improve fluorescent OLED characteristics}

Because the spin-coating rotation speed directly affects the film thickness, we fixed the spincoating time at 35 seconds from the beginning of the experiment. The rotation speed of the spina-NPD:NPB layer (3500, 4000, 4500 and 5000 r.p.m.) was varied to study how the device optoelectronic characteristic was affected by the rotation speed of spin-coating. The device structure was PET/ ITO $(160 \mathrm{~nm}) /$ spin-coated (NPB:a-NPD)+THF (different rotation speed)/evaporated NPB (41 nm)/Alq3 (52 nm)/Bpy-OXD (15 nm)/LiF (0.5 nm)/ Al (135 $\mathrm{nm})$. The device energy band structure was shown in Figs. 7(a). Because the coated film 
thickness will become thick under lower rotation speed, from Fig. 7(b), we can see the lowest current density flowing through the device at the lowest rotation speed (3500 r.p.m.). According to the Mott-Gurney rule [17], we know that the current density presents an inverse-proportion relation with the thickness, and the greatest NPB spin-coating layer thickness can be estimated to appear at a rotation speed of 3500 r.p.m. However, the layer thickness will become thinner as the rotation speed increases and the current density will increase accordingly. However, at 5000 r.p.m., we found that the device current density decreased. The major reason results from too high rotation speed which causes the centrifugal force to become too strong, preventing the NPB+THF solution from attaching onto the ITO surface; hence, the film thickness becomes uneven. From Fig. 8 luminancecurrent density characteristic curve, we can observe the same trend in the current densityvoltage curve. Hence, we determined that 4500 r.p.m. is the optimal spin-coating parameter to get the best optoelectronic characteristic.

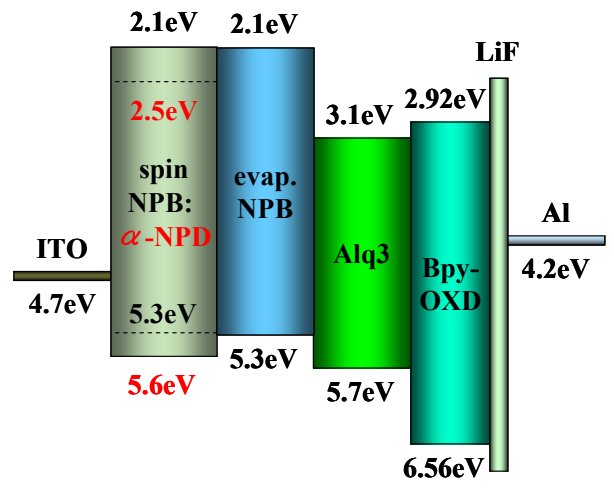

(a)

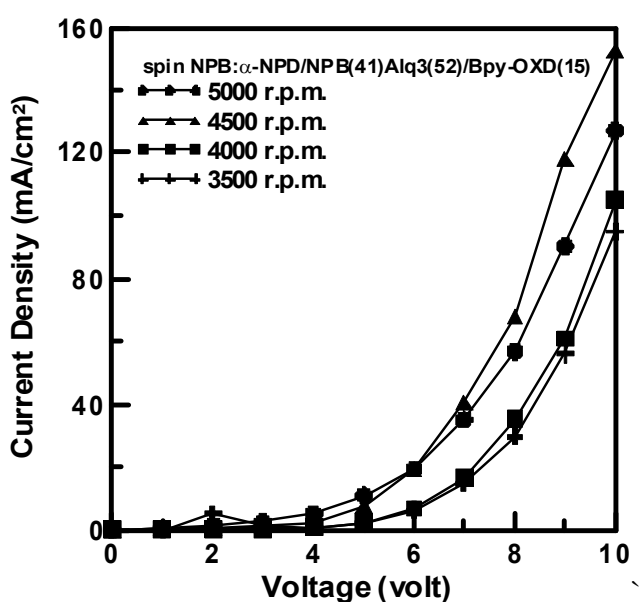

(b)

Fig. 7. (a) The energy band structure of the device with spin-coating (NPB:a-NPD)+THF buffer layer; (b) J-V characteristics for different rotation speeds 


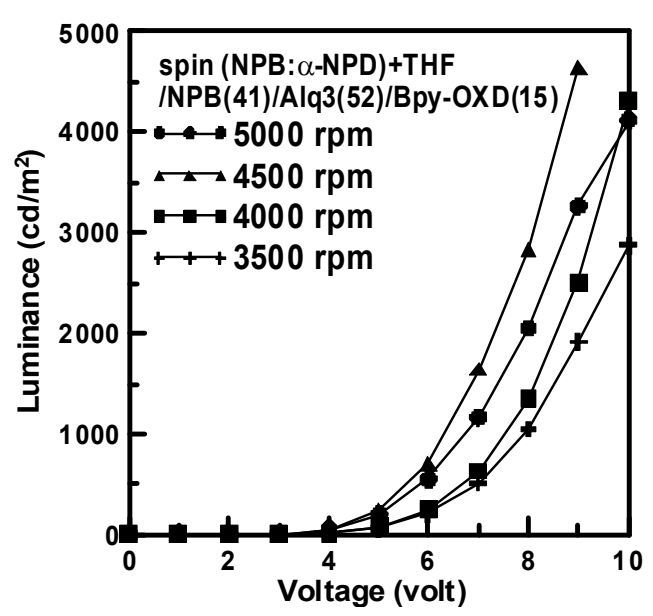

Fig. 8. L-V characteristics for spino-coating (NPB:a-NPD)+THF with different rotation speeds

To further verify the first HTL (NPB:a-NPD)+THF manufacturing process versus improving the device optoelectronic characteristics, the following experiment was conducted. Devices with PET/ITO(160 nm)/ HTL/Alq3(52 nm)/Bpy-OXD(15 nm)/LiF(0.5 nm)/Al(135 nm) structures wherein the HTL was produced via the spin-coating or thermal-evaporation process or both, are shown in Table 3.

Under same current density, the optoelectronic characteristics of Devices G1 and G2 (employing both spin-coated and evaporated double HTLs structures) were higher than that of traditional devices made with single HTL using only thermal-evaporation (Device G3), as shown in Fig. 9(a) and 9(b). The device characteristics with double HTLs were also found better than those with the single HTL spin-coated structure (NPB:a-NPD)+THF only (Device G4). Because spin-coating the film in the amorphous mode on the ITO surface does not easily generate pin holes, and the organic layer contact with the ITO becomes tighter, the HTL surface roughness can be greatly improved [18-21]. Therefore, the holes are injected more easily from the ITO electrode into the NPB layer. Furthermore, the optoelectronic characteristics of Device G1 were better than Device G2 because spin-coating (NPB:aNPD)+THF has similar p-type doping properties that enable holes to be injected efficiently [22]. NPB and a-NPD co-doping will produce band bending and enable the holes to tunnel from the ITO electrode into the HTL, forming an Ohmic contact interface [23]. Consequently the Device G1 exhibited the best performances than the other devices. Fourier Transform Infrared Spectroscopy (FTIR) was also performed on the HTL films to study the variation in molecular structure. Moreover, from the lifetime test results shown in Fig. 10, the lifetime of Device G1 was the longest, increased by about $41 \%$ longer than Device G3 (fabricated without spin-coating (NPB:a-NPD)+THF layer). 


\begin{tabular}{|c|c|c|}
\hline \multirow{2}{*}{ Devices } & \multicolumn{2}{|l|}{ HTL thickness } \\
\hline & (NPB:a-NPD) dissolved in THF then spin-coating & evaporate \\
\hline \multirow{2}{*}{ G1 } & spin (NPB:a-NPD)+THF & NPB \\
\hline & $58 \mathrm{~nm}$ & $41 \mathrm{~nm}$ \\
\hline \multirow{2}{*}{ G2 } & spin NPB +THF & NPB \\
\hline & $37 \mathrm{~nm}$ & $41 \mathrm{~nm}$ \\
\hline \multirow{2}{*}{ G3 } & spin (NPB: $\alpha-N P D)+T H F$ & NPB \\
\hline & $0 \mathrm{~nm}$ & $41 \mathrm{~nm}$ \\
\hline \multirow{2}{*}{ G4 } & spin (NPB: $\alpha-N P D)+T H F$ & NPB \\
\hline & $58 \mathrm{~nm}$ & $0 \mathrm{~nm}$ \\
\hline
\end{tabular}

Table 3. Different parameters of hole transport layer structures (unit: $\mathrm{nm}$ )

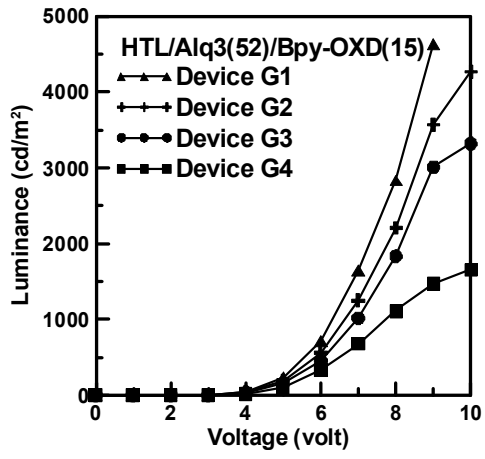

(a)

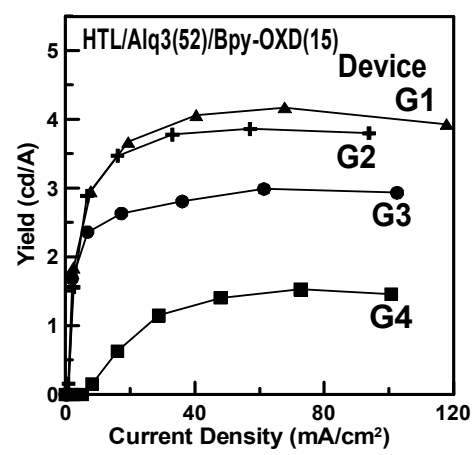

(b)

Fig. 9. (a) L-V and (b) Y-J characteristics for different HTL structures

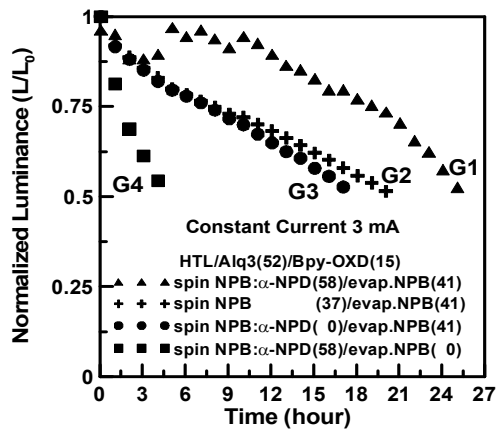

Fig. 10. The lifetime of flexible OLEDs with different HTL structures, and the devices were packaged by evaporating m-MTDATA $500 \mathrm{~nm}$ on the device surface

\section{Conclusion}

This research successfully improved the luminance efficiency and lifetime of flexible fluorescent and phosphorescent organic light emitting diodes by optimizing organic layer thicknesses or inserting a spin-coated buffer layer. From the results, the best phosphorescent device structure (ITO/ NPB (50nm)/ Ir(ppy) $3: \mathrm{CBP}(40 \mathrm{~nm}) / \mathrm{TPBi}(10 \mathrm{~nm}) /$ Alq3 (50nm)/ LiF 
$(0.5 \mathrm{~nm}) / \mathrm{Al}(65 \mathrm{~nm}))$ has a maximum luminance efficiency of $34.2 \mathrm{~cd} / \mathrm{A}$ by optimizing organic layer thicknesses. This device performance improvement is attributed to increased hole injection and improved hole-electron balance. In addition, extending the charge carrier recombining area and using more suitable HBL material and suitable thickness of its thin film will gradually increase and improve the luminance efficiency of the device. Comparing devices with TPBi and BCP as the HBL, it was found that devices fabricated with TPBi as the HBL exhibited better luminance efficiency than BCP.

We also discussed the effect with/without a spin-coated buffer layer on device performance. It was found that devices inserted with a spin-coated buffer layer had better brightness, luminance efficiency and lifetime than conventional devices (without spin-coating buffer layer). Furthermore, the research demonstrated the advantage of using spin-coating codoping (NPB:a-NPD)+THF (exhibit the similar p-type doping properties and metal-like Ohmic contact interface) plus thermal-evaporation in fabricating flexible fluorescent organic light emitting diodes with double-hole transport layer structures. The performance of the best Device G1 exhibited a luminance of $4634 \mathrm{~cd} / \mathrm{m}^{2}$ at $9 \mathrm{~V}$ and a luminance efficiency 4.18 $\mathrm{cd} / \mathrm{A}$ at $68 \mathrm{~mA} / \mathrm{cm}^{2}$. Compared with the single thermal-evaporated NPB only HTL structure, the luminance efficiency of device with spin-coated (NPB:a-NPD)+THF as buffer layer was increased by about $1.32 \mathrm{~cd} / \mathrm{A}$ and its half-lifetime was increased by about $41 \%$ longer than the device without spin-coated buffer layer.

\section{References}

[1] C. W. Tang, and S. A. VanSlyke, (1987). Organic electroluminescent diodes. Appl. Phys. Lett., Vol. 51, pp. 913-915.

[2] Z. Liu, J. Pinto, J. Soares, E. Pereira, (2001). Efficiency multilayer organic light emitting diode. Synth. Met., Vol. 122, pp. 177-179.

[3] Y. Shirota, Y. Kuwabara, H. Inada, T. Wakimoto, H. Nakada, Y. Yonemoto, S. Kawami, K. Imai, (1994). Multilayered organic electroluminescent device using a novel starburst molecule, 4,4 ,4 -tris(3-methylphenylphenylamino)triphenylamine, as a hole transport material. Appl. Phys. Lett., Vol. 65, No. 7, pp. 807-809.

[4] J. Shi, C.W. Tang, (1997). Doped organic electroluminescent devices with improved stability. Appl. Phys. Lett., Vol. 70, No. 13, pp. 1665-1667.

[5] C. Giebeler, H. Antoniadis, D. D. C. Bradley, Y. Shirota, (1999). Influence of the hole transport layer on the performance of organic light-emitting diodes. J. Appl. Phys., Vol. 85, No. 1, pp. 608-615.

[6] Z. Liu, Z. Weiming, J. Rongbin, Z. Zhilin, J. Xuejing and X. Minzhao, (1996). Organic thin film electroluminescent devices with $\mathrm{ZnO}: \mathrm{Al}$ as the anode. J. Phys.: Condens. Matter., Vol. 8, pp. 3221-3228.

[7] F. Zhu, B. Low, K. Zhang, and S. Chua, (2001). Lithium-fluoride-modified indium tin oxide anode for enhanced carrier injection in phenyl-substituted polymer electroluminescent devices. Appl. Phys. Lett., Vol. 79, pp. 1205-1207.

[8] W. L. Yu, J. Pei, Y. Cao, and W. Huang, (2001). Hole-injection enhancement by copper phthalocyanine $(\mathrm{CuPc})$ in blue polymer light-emitting diodes. J. Appl. Phys., Vol. 89 , pp. 2343-2350. 
[9] S. A. Carter, M. Angelopoulous, S. Karg, P. J. Brock, and J. C. Scott, (1997). Polymeric anodes for improved polymer light-emitting diode performance. Appl. Phys. Lett., Vol. 70, pp. 2067-2069.

[10] J. C. Scott, S. A. Carter, S. Karg, and M. Angelopoulous, (1997). Polymeric anodes for organic light-emitting diodes. Synth. Met., Vol. 85, pp. 1197-1200.

[11] T. M. Brown, J. S. Kim, R. H. Friend, F. Cacialli, R. Daik, and W. J. Feast, (1999). Built-in field electroabsorption spectroscopy of polymer light-emitting diodes incorporating a doped poly(3,4-ethylene dioxythiophene) hole injection layer. Appl. Phys. Lett., Vol. 75, pp. 1679-1681.

[12] M. A. Baldo, S. Lamansky, P. E. Burrows, M. E. Thompson, and S. R. Forrest, (1999). Very high-efficiency green organic light-emitting devices based on electrophosphorescence. Appl. Phys. Lett., Vol. 75, pp. 4-6.

[13] C. Adachi, M. A. Baldo, M. E. Thompson, and S. R. Forrest, (2000). High-efficiency organic electrophosphorescent devices with tris(2-phenylpyridine)iridium doped into electron-transporting materials. Appl. Phys. Lett., Vol. 77, pp. 904-906.

[14] M. Ikai, S. Tokito, Y. Sakamoto, T. Suzuki and Y. Taga, (2001). Highly efficient phosphorescence from organic light-emitting devices with an exciton-block layer. Appl. Phys. Lett., Vol. 79, pp. 156-158.

[15] T. D. Anthopoulos, Jonathan P. J. Markham, E. B. Namdas, Ifor D. W. Samuel, S. C. Lo and P. L. Burn, (2003). Highly efficient single-layer dendrimer light-emitting diodes with balanced charge transport. Appl. Phys. Lett., Vol. 82, pp. 4824-4826.

[16] B. D. Chin, M. C. Suh, M. H. Kim, S. T. Lee, H. D. Kim, and H. K. Chung, (2005). Carrier trapping and efficient recombination of electrophosphorescent device with stepwise doping profile. Appl. Phys. Lett., Vol. 86, pp. 133505-1 4.

[17] M. A. Lambert and P. Mark, Current Injection in Solids (Academic Press, New York, 1970).

[18] Y. S. Tsai, S. H. Wang and S. L. Chen, (2009). Performance Improvement of Flexible Organic Light-Emitting Diodes with Double Hole Transport Layers by SpinCoating and Evaporation. Jpn. J. Appl. Phys., Vol. 48, pp. 052103-1 3.

[19] Y. S. Tsai, S. H. Wang, S. Y. Chen, S. Y. Su, F. S. Juang, (2009). Efficiency improvement of flexible fluorescent and phosphorescent organic light-emitting diodes by inserting a spin-coating buffer layer. Thin Solid Films, Vol. 517, pp. 5334 5342.

[20] S. Y. Su, F. S. Juang and Y. S. Tsai, (2006). High Efficiency Flexible Organic LightEmitting Diodes by Phosphorescent Dopant. Master thesis of Graduate Institute of Electro-Optical and Materials Science, National Formosa University.

[21] S. L. Chen, F. S. Juang and Y. S. Tsai, (2007) Double Hole Transport Layers Deposited by Spin-Coating and Thermal-Evaporating for Flexible Organic Light Emitting Diodes. Master thesis of Graduate Institute of Electro-Optical and Materials Science, National Formosa University.

[22] A. Yamamori, C. Adachi, T. Koyama and Y. Taniguchi, (1998). Doped organic light emitting diodes having a 650-nm-thick hole transport layer. Appl. Phys. Lett., Vol. 72, pp. 2147 2149.

[23] J. Blochwitz, M. Pfeiffer, T. Fritz, and K. Leo, (1998). Low voltage organic light emitting diodes featuring doped phthalocyanine as hole transport material. Appl. Phys. Lett., Vol. 73, pp. 729 731. 


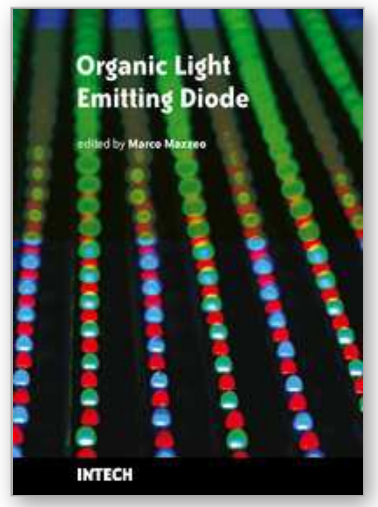

\author{
Organic Light Emitting Diode \\ Edited by Marco Mazzeo
}

ISBN 978-953-307-140-4

Hard cover, 224 pages

Publisher Sciyo

Published online 18, August, 2010

Published in print edition August, 2010

Organic light emitting diodes (OLEDs) have attracted enormous attention in the recent years because of their potential for flat panel displays and solid state lighting. This potential lies in the amazing flexibility offered by the synthesis of new organic compounds and by low-cost fabrication techniques, making these devices very promising for the market. The idea that flexible devices will replace standard objects such as television screens and lighting sources opens, indeed, a new scenario, where the research is very exciting and multidisciplinary. The aim of the present book is to give a comprehensive and up-to-date collection of contributions from leading experts in OLEDs. The subjects cover fields ranging from molecular and nanomaterials, used to increase the efficiency of the devices, to new technological perspectives in the realization of structures for high contrast organic displays and low-cost organic white light sources. The volume therefore presents a wide survey on the status and relevant trends in OLEDs research, thus being of interest to anyone active in this field. In addition, the present volume could also be used as a state-of-the-art introduction for young scientists.

\title{
How to reference
}

In order to correctly reference this scholarly work, feel free to copy and paste the following:

Fuh-Shyang Juang, Yu-Sheng Tsai, Shun-Hsi Wang, Shin-Yuan Su, Shin-Liang Chen and Shen-Yaur Chen (2010). Optimum Structure Adjustment for Flexible Fluorescent and Phosphorescent Organic Light Emitting Diodes, Organic Light Emitting Diode, Marco Mazzeo (Ed.), ISBN: 978-953-307-140-4, InTech, Available from: http://www.intechopen.com/books/organic-light-emitting-diode/optimum-structure-adjustment-for-flexiblefluorescent-and-phosphorescent-organic-light-emitting-diod

\section{INTECH}

open science | open minds

\section{InTech Europe}

University Campus STeP Ri

Slavka Krautzeka 83/A

51000 Rijeka, Croatia

Phone: +385 (51) 770447

Fax: +385 (51) 686166

www.intechopen.com

\section{InTech China}

Unit 405, Office Block, Hotel Equatorial Shanghai

No.65, Yan An Road (West), Shanghai, 200040, China 中国上海市延安西路65号上海国际贵都大饭店办公楼 405 单元

Phone: +86-21-62489820

Fax: $+86-21-62489821$ 
(C) 2010 The Author(s). Licensee IntechOpen. This chapter is distributed under the terms of the Creative Commons Attribution-NonCommercialShareAlike-3.0 License, which permits use, distribution and reproduction for non-commercial purposes, provided the original is properly cited and derivative works building on this content are distributed under the same license. 